\title{
Prevention of iatrogenesis in obstetrics: Comments from the vision of the family doctor
}

\author{
Jose Luis Turabian* \\ Health Center Santa Maria de Benquerencia. Regional Health Service of Castilla la Mancha (SESCAM), Toledo, Spain
}

Medical errors and adverse effects are becoming more frequent. It is estimated that $20 \%$ of patients present an adverse event after hospital discharge and that $40 \%$ of hospitalized patients are discharged with the results of the pending tests [1]. Litigation in medical practice and in obstetrics and gynaecology is becoming a global problem. Therefore, it is necessary to know what constitutes negligence and what extent it is preventable [2]. Obstetric care is characterized by generally younger ages among patients, their low frequency of co morbidities and high expectations for successful outcomes of care. However, some factors can increase obstetric risk and favour the appearance of preventable incidents, iatrogenic, and adverse effects [3].

Iatrogenia often has its origin in the doctor-patient relationship. Iatrogenia often has its origin in the doctor-patient relationship. And in this context perhaps some comments from the vision of general medicine may be of some use for obstetrics and gynecology. General medicine is the only discipline that is defined in terms of relationships, especially of doctor-patient relationships (other fields are defined in terms of content, such as diseases, systems or technologies); here, the relationship is a priority over content: we know people before they express diseases. Of course, doctors from other medical specialties are also related to patients, but in obstetrics and gynecology this relationship is especially important. Thus, perhaps from the perspective of general medicine, some important elements of the obstetric/gynecologicalpatient relationship can be pointed out to avoid iatrogenia [4,5].

On the one hand, the increasing complexity of modern medicine has exceeded the ability of an individual physician to provide care safely. On the other hand, with technological and clinical advances, the general public has acquired a great expectation of favorable results, considering that any deviation from this expectation should be the responsibility of somebody, usually the doctor and / or the staff that provided should be considered. Consequently, physicians should be less paternalistic in assuming that they only have the answers and be more willing to work collaboratively with each other, with other health professionals and dialogue with patients [6].

The doctor must bear in mind that the possibilities of committing iatrogenia increase in situations where the suggestibility of the person served is increased for some reason; this is precisely the situation of the pregnant woman and the woman in labor. It is important to note that in the obstetricians there is a notable concern to prevent iatrogenias, and usually their professional relationships are of great quality, as during their daily exercise they realize the negative effects of the anguish on the physiological mechanisms of childbirth, and they always keep in mind that, in their interpersonal relationship with the pregnant woman, the most significant mission is to eliminate distressing conditions related to childbirth and not to create them through professional errors.
Of course, the prevention of iatrogenia caused by mechanisms unrelated to interpersonal communication, such as those related to deficient surgical techniques, is a task of the first order. These iatrogenia are actually the ones that can be more easily avoided, since the rest require for their prevention an absolute conscious control of verbal and non-verbal communications, and within these the tactile and instrumental relationship with the pregnant woman, as well as a permanent planning about the resources that must be used to meet medical goals. Many doctors are not "synchronized" with patients and, as a result, they often do poor service or commit preventable medical errors. Part of the solution to these problems is that the doctor-patient relationship is "patient-centered" [7], or essentially, more empathic with the suffering of the patients. Physicians practicing obstetrics should adopt a flexible approach and match the degree and type of intervention to actual patient needs [8].

This also means that the doctor working from an educational perspective; it means being aware that the doctor performs a work of "creating contexts" through the relationships and communications that he has established with the patients and their family in the consultation or hospital. Any interaction or relationship with the patient create contexts Context creation is the result of implementing a series of professionalpatient relationship strategies: 1) one-way informational strategy; 2) persuasive or advisory strategy: the relationship between professional and patient is "convergent" (doctor shows interest or concern for the other, or he adjusts to the other) [9,10]; and 3) significant or "coaching" strategy: the relationship between professional and patient is "sharing" and "help". It is to see patients from new perspectives. To see not only his words, but also something else; everything that surrounds him and everything in the space between us, just as in a field of wheat in the summer, that you can almost see the breeze that curls the wheat. Helping people has nothing to do with psychology, but to be human with the one who suffers, to advance with another person as the parts that form a whole [11].

Therefore, building a relationship between people creates social contexts. The professional-patient relationship contextualizes the work of the professional. The work of the doctor is not a series of tasks but a series of relationships-social connections where the tasks are immersed. The contextualization of doctor work is a type of relationship and connection between people [12-14]. Involving physicians in a better

*Correspondence to: Jose Luis Turabian, Health Center Santa Maria de Benquerencia, Regional Health Service of Castilla la Mancha (SESCAM), Toledo, Spain, E-mail: jturabianf@hotmail.com

Received: October 05, 2018; Accepted: October 12, 2018; Published: October 18,2018 
relationship with the patient, has positive repercussions in improving the process, obtaining data, safety, and quality of care [15].

It is said that the doctor who cares to psychologically help their patients with major or minor psychotherapeutic techniques -and this is usual in obstetricians-, is practically impossible to commit iatrogenia, since in the doctor's professional relations with the patient there are only two opposite alternatives: psychotherapy in some of its variants or iatrogenia. Example of this opposition is the iatrogenic by omission that occurs when information of high anxiolytic significance is undervalued by the doctor and their communication is not planned.

There is, however, a type of iatrogenia often derived from the medical tensions themselves during the delivery of a dystocic birth and is the one produced by the non-verbal communication of the anguish of the doctor or another member of the team, in a situation of stress. It is also advisable to avoid comments regarding the need to apply forceps, since this instrumentation is popularly considered as a sign that there are serious complications. Likewise, the administration of oxygen must always be accompanied by information that this measure is helpful during the expulsive period, to avoid in this way the usual assessments of a situation of seriousness.

Finally, it is necessary to emphasize that when the members of the obstetric team forget to approach the parturient effectively to transmit messages of understanding, safety and solidarity during their labour, they commit the most unnoticed of the iatrogenia in the obstetric work: the one produced by the disability of the doctor to be in the place of the parturient, more than ever before, in need of support [1].

\section{References}

1. Kondro W (2010) Medical errors increasing because of complexity of care and breakdown in doctor-patient relationship, physician consultant says. CMAJ; 182(13). http://www.cmaj.ca/cgi/content/full/182/13/E645?etoc
2. Gowda SL, Bhandiwad A, Anupama NK (2016) Litigations in Obstetric and Gynecological Practice: Can it be prevented? A Probability to Possibility. J Obstet Gynaecol India 66: 541-547. [Crossref]

3. Aibar L, Rabanaque MJ, Aibar C, Aranaz JM, Mozas J (2015) Patient safety and adverse events related with obstetric care. Arch Gynecol Obstet 291: 825-830. [Crossref]

4. Donaldson MS, Vanselow NA (1996) The nature of primary care. J Fam Pract 42: 113-116. [Crossref]

5. Turabian JL (1995) Cuadernos de Medicina de Familia y Comunitaria. Una introducción a los principios de Medicina de Familia. [Family and Community Medicine notebooks. An Introduction to the Principles of Family Medicine]. Madrid: Díaz de Santos. http:// www.amazon.co.uk/Cuadernos-medicina-familia-y-comunitaria/dp/8479781920

6. Rodrigues Domingues AP, Belo A, Moura P, Nuno Vieira D (2015) Medico-legal litigation in Obstetrics: a characterization analysis of a decade in Portugal. Rev Bras Ginecol Obstet 37:241-246. [Crossref]

7. Kuehn BM (2012) Patient-Centered Care Model Demands Better Physician-Patient Communication. JAMA 307: 441-442.

8. Brody H, Thompson JR (1981) The maximin strategy in modern obstetrics. J Fam Pract 12: 977-986. [Crossref]

9. Johnston CA, Stevens BE (2013) Motivational Interviewing in the Health Care Setting. Am J Lifestyle Med 7: 246-249.

10. Berkowitz SA, Johansen KL (2012) Does motivational interviewing improve outcomes? Arch Intern Med 172: 463-464. [Crossref]

11. Shem S (1997) Mount Misery. IVY BOOKS.

12. Turabian JL (2005) Inteligencia contextual. [Contextual intelligence]. JANO; LXIX (1571): 10. http://www.jano.es/ficheros/sumarios/1/69/1571/10/1v69n1571a13076911 pdf001.pdf

13. Boxer H, Snyder S (2009) Five communication strategies to promote self-management of chronic illness. Fam Pract Manag 16: 12-16. [Crossref]

14. Turabián JL, Pérez-Franco B (1998) General practitioners' health education and healthy lifestyles: is there any choice to passivity, which is forced by technical and ethical problems? Med Clin (Barc) 110: 45.

15. Turabián JL, Pérez Franco B (2008) The Effect of Seeing the Sea for the First Time. An Attempt at Defining the Family Medicine Law: The Interview is Clinical Medicine. Aten Primaria 40:565-566. [Crossref]

Copyright: (C2018 Turabian JL. This is an open-access article distributed under the terms of the Creative Commons Attribution License, which permits unrestricted use, distribution, and reproduction in any medium, provided the original author and source are credited. 